\title{
Population and habitat use of Asian elephants (Elephas maximus) and five ungulate species in Khao Ang Rue Nai Wildlife Sanctuary, Chachoengsao Province, Thailand
}

\author{
KUSUMA MENKHAM, RONGLARP SUKMASUANG, MANANYA PLA-ARD, KHWANRUTAI CHARASPET, \\ TARAPONE PANGANTA, YUNGYUT TRISURAT ${ }^{\bullet}$, NARIS BHUMPAKPHAN \\ Department of Forest Biology, Faculty of Forestry, Kasetsart University, 50 Phaholyothin Road, Chatuchak, Bangkok 10900, Thailand. \\ Tel. +66-257-90176 Fax. +66-294-28107. `email: fforyyt@ku.ac.th, fforrls@ku.ac.th
}

Manuscript received: 19 June 2019. Revision accepted: 20 July 2019

\begin{abstract}
Menkham K, Sukmasuang R, Pla-Ard M, Charaspet K, Panganta T, Trisurat Y, Bhumpakphan N. 2019. Population and habitat use of Asian elephants (Elephas maximus) and five ungulate species in Khao Ang Rue Nai Wildlife Sanctuary, Chachoengsao Province, Thailand. Biodiversitas 20: 2213-2221. This study on the Asian elephant (Elephas maximus) population, habitat use and the diel activity patterns of elephants and five species of large even-toed ungulates was conducted between March 2017 and March 2018 in Khao Ang Rue Nai Wildlife Sanctuary, Chachoengsao Province using intensive camera trapping. Fifty-eight camera traps were deployed, adding up to a total of 4,463 trap nights and revealing 1,760 independent encounters. Six species of mammals were recorded, including the Asian elephant (Elephas maximus) and five species of large even-toed ungulates; the gaur (Bos gaurus), the banteng (Bos javanicus), the sambar deer (Rusa unicolor), the wild boar (Sus scrofa), and the muntjac (Muntiacus muntjak). The abundance analysis reflected that the probability occupancy of the elephant was $0.92(\mathrm{SE}=0.04)$; in dry seasons $0.97(\mathrm{SE}=0.04)$ and in wet seasons 0.90 $(\mathrm{SE}=0.83)$. The population of elephants within the study site of $87.95 \mathrm{~km}^{2}$ was within $79.51-334.15$ individuals. The elephant age classes were identified as adult, sub-adult, juvenile, and calf with percentages of $77.85 \%, 5.71 \%, 9.28 \%$, and $7.14 \%$, respectively. The adult male to adult female sex-ratio was 1: 1.39 and the adult female per calf ratio was 1: 0.12 . The percentage of the calf to adult female ratio was $9.17 \%$. Maximum Entropy analysis revealed that saltlicks and artificial water sources were the environmental factors that had the most influence on the probability of occurrence of the elephant (all year). We found that the diel activity pattern of the elephants was strongly nocturnal (85\% recorded between 18.00-05.59 hours). Temporal overlapping was seen between elephants and gaurs, bantengs and sambar deer in order. Suggestions for area management include improvement of water sources, salt licks, grassland management, and providing education, publicization, and strict control to decrease human activities within the protected area. There also should be continuous studies to monitor the population and the ecology of these species.
\end{abstract}

Keywords: Camera trap, Khao Ang Rue Nai Wildlife Sanctuary, relative abundance, ungulate species, wild elephant

\section{INTRODUCTION}

The increase in the need for natural resources to support the growing human population has caused loss, degradation, and conflict between humans and wildlife (FAO 2009). This problem has increased in severity globally, affecting food security, society, economy, environment, and overall natural resources (Seoraj-Pillai and Pillay 2017). In Asia, the wildlife species that have conflict with humans are mainly large carnivores (e.g. tigers, leopards, lions, and snow leopards) and wild elephants, which have reports of conflicts in every range country (e.g. Barnes 1996; Treves and Naughton-Treves 1999; Madhusudan 2003; Zang and Wang 2003). The conflict between humans and elephants in Thailand has been long reported for up to 100 years (Faculty of Forestry 2013) when more than 1,000 wild elephants came to forage in agricultural land within the Thung Rangsit area, located near with the north part of Bangkok. At present, humanelephant conflicts have been reported around the borders of 42 of the 69 protected areas that still contain elephants within Thailand (Hedges et al. 2008). The highest conflicts in the country are seen around the Eastern forest complex (Faculty of Forestry 2013). One of the main reasons is that this area comprises mostly connected flatlands, with agricultural areas right up to the borders of the protected areas containing elephants, causing more wild elephants to be drawn from the forests. Furthermore, roads have been cut through the forests, and agricultural products are transported through the forests causing a change in the elephants' behavior, being attracted to the taste of these agricultural products. The lack of water sources within the protected areas, especially in the dry season, is one of the causes for many elephants in the Eastern forest complex of Thailand to leave to protected areas (Wanghongsa et al. 2008). The number of elephants reported within Khao Ang Rue Nai Wildlife Sanctuary in 2002 was 136 elephants, which increased to approximately 200 elephants in 2013 (Faculty of Forestry (2013). The number of elephants reported in the 5 protected areas within the Eastern forest complex including Khao Ang Rue Nai Wildlife Sanctuary, Khao Soi Dao Wildlife Sanctuary, Khao Sip Ha Chan National Park, Khao Kitchakood National Park, and Khao Chamao-Khao Wong National Park was 364 elephants, 
with 236 individuals living in Khao Ang Rue Nai Wildlife Sanctuary estimated by direct counting (Vinitpornsawan et al. 2015).

The increase in the elephant population within the Eastern forest complex is moving in the same direction as the increase in agriculture area (Faculty of Forestry 2013) causing increasing conflict between people and wild elephants that continue to be serious. Studies on the wild elephant population, sex ratio, age structure and the increase in population, as well as the distribution and habitat use, the suitable habitat size and the spatial and temporal relationships between wild elephants and other herbivorous species within Khao Ang Rue Nai Wildlife Sanctuary, have never been conducted before.

The results of this study will provide a better understanding of the interaction between wild elephants and other herbivorous species that are direct resource competitors affecting the carrying capacity of the habitat (Durant 1998). Identification of the cause of animals leaving the protected areas is important for dealing with the migration from the protected areas in several ways. Even though there have been studies on the elephant population count in the area, using line-transect with the indirect method, counting around water sources (Wanghongsa et al. 2004) or direct counting (Vinitpornsawan et al. 2015), there has never been a study using the camera trapping method. Photographs taken can give accurate results, which can benefit problem management and more effective elephant conservancy programs. The objectives were to study the population abundance, age structure, sex ratio, reproductive rate and recruitment rate of wild Asian elephants, to study habitat use of wild Asian elephants in Khao Ang Rue Nai Wildlife Sanctuary and to study the activity cycle of wild elephants and the relationship with other large even-toed ungulates in Khao Ang Rue Nai Wildlife Sanctuary.

\section{MATERIALS AND METHODS}

\section{Study area}

Khao Ang Rue Nai Wildlife Sanctuary (KARN) in eastern Thailand $\left(13^{\circ} 00^{\prime}-13^{\circ} 32^{\prime} \mathrm{N}, 1^{\circ} 101^{\circ} 40^{\prime}-102^{\circ} 09^{\prime} \mathrm{E}\right)$ encompasses $1,064.44 \mathrm{~km}^{2}$ (Figure 1). The climate is monsoonal, with distinctive rainy or southwest monsoon season (mid-May to mid-October), winter or northeast monsoon season (mid-October to mid-February), and summer or pre-monsoon season (mid-February to midMay) seasons. Average annual rainfall is an average of $1,888.9 \mathrm{~mm}$, and average temperature all year round is $28.03^{\circ} \mathrm{C}$ (ranged between 26.7-29.1 ${ }^{\circ} \mathrm{C}$ ) (Thai Meteorological Department 2019). The majority of the vegetation is lowland rainforest at $<200 \mathrm{~m}$ elevation. Human activity varies throughout the sanctuary and is influenced by ranger patrols, tourist and villagers entering the area. Illegal hunting targeting birds and small mammals occurs occasionally in the sanctuary. Additionally, there have been cases of larger mammals such as gaur Bos gaurus and banteng Bos javanicus and the Asian elephant (Elephas maximus) being injured by snares (Jenks et al. 2012; Wattanaaungkool 2017).

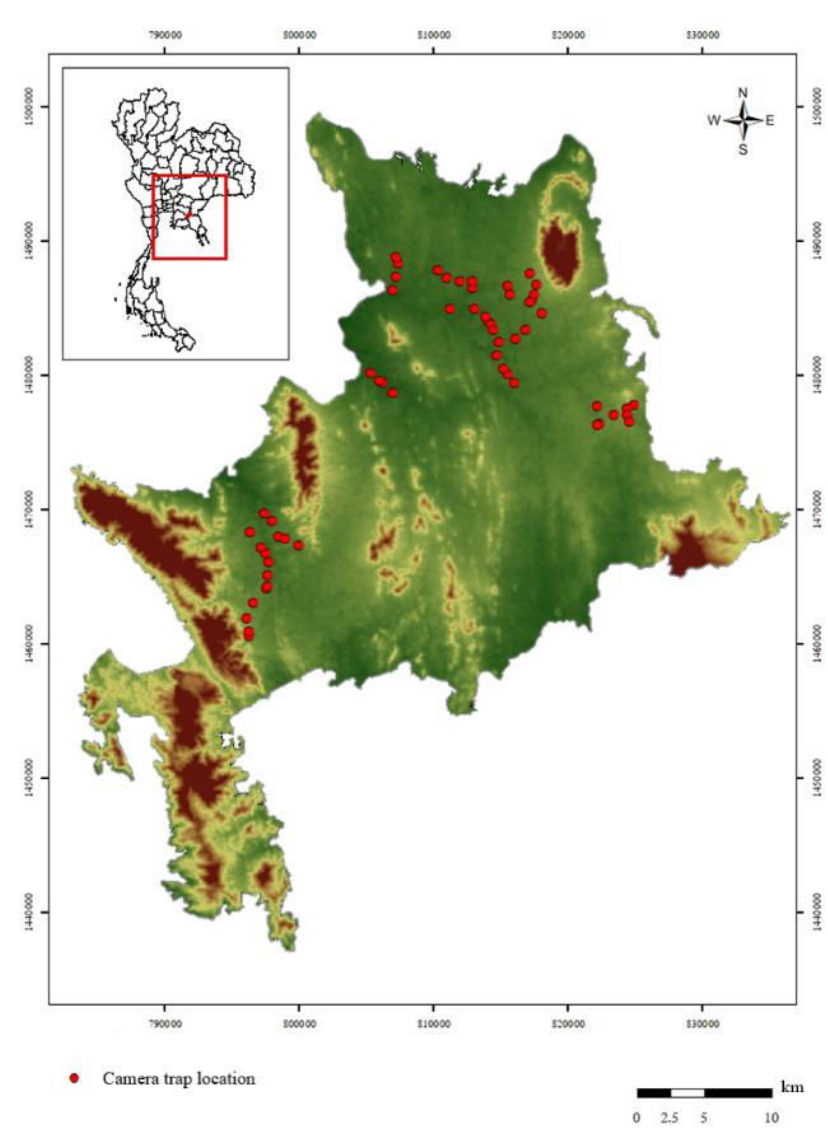

Figure 1. Map of Khao Ang Rue Nai Wildlife Sanctuary and the camera trap locations ( $\mathrm{n}=58$ with 4,463 trap nights totally). Source: Department of Land Development (2016)

\section{Field data collection}

The locations of the camera traps in this study were chosen after surveying the study area and choosing suitable locations according to the appearance of elephant tracks. In the dry season, camera traps were placed near water sources, which is suitable for an elephant population count (Wanghongsa 2004) and these became the main locations to set up camera traps during the dry season (Varma et al. 2006; 2012), followed by around saltlicks and along animal trails (Rovero and Marshall 2009). This study focused on wild Asian elephant and 5 species of large even-toed ungulates including gaur, banteng, sambar deer, wild boar, and red muntjac.

Twenty camera traps were placed $0.05-0.75$ meters from the ground, approximately $1 \mathrm{~km}$ apart (Chaiyarat et al. 2015) and placed along the animal trails at a distance far enough for the camera to take photographs of every wildlife species. The cameras were set to take photographs 24 hours a day, and take 3 consecutive photographs every 10 seconds after being triggered (Tropical Ecology Assessment and Monitoring Network 2008). They were left for 60 days before the team went in to check the cameras and change locations (Tropical Ecology Assessment and Monitoring Network 2008) to cover the study area within Khao Ang Rue Nai Wildlife Sanctuary. The coordinates of each camera trap location were recorded using a GPS tracking device and transferred into the Geographic Information System (GIS) software. 


\section{Data analysis}

1. The photographs recorded by the camera traps were classified following the method of O' Brien et al. (2003), which is (i) consecutive photographs of the same species taken in the same location within 30 minutes will be counted as 1 incidence, (ii) consecutive photographs of a species at the same location within 30 minutes but can be identified as different individuals will be counted as different incidences and (iii) non-consecutive photographs at different times and locations will be counted as 2 incidences.

2. Arrange the images by date-month-year, time and camera location. Then identify the species, the number of animals, sex, and age. Then check the accuracy of the information specified for analysis in the next step.

3. Identify individuals, age, and sex using the external characteristics that are different in each of the wild elephants from the photographs recorded by the camera traps. Record the details of the photographs, especially the photographs that can be classified, and record the date and time that are shown in the photograph (Siripattaranugul et al. 2015). The characteristics of the photographs that were classified were chosen followed the method of Varma et al. (2006), which had 3 characteristics including (i) quality: the sex and age of the elephant can be identified, (ii) clarity: each photograph has to be clear, the flash reaches the elephant and picture is in focus and (iii) the position within the image: suitable distance from camera trap, full body from head to tail could be seen and the shape of the elephant could be classified in detail.

4. Classification of the elephant population structure, sex, and age of the elephant from the photograph by considering the size and shape, height and external organs. Analyze from the shoulder height and divide into 4 classes including calf, juvenile, sub-adult and adult (Arivazhagan and Sukumar 2008; Rowcliffe et al. 2012; Varma et al. 2012).

5. The Relative Abundance Index (RAI) of the elephant population was calculated by multiplying the Photographic Rate by 100 and dividing by the number of trap nights (Kawanishi et al. 1999; Azlan and Sharma 2006) following the equation.

Relative Abundance Index $(\mathrm{RAI})=\frac{\text { Number of elephant photographs }}{\text { Trap night }} \times 100 \%$

6. The Patch Occupancy was calculated by identifying the information obtained in each $1 \times 1$ grid, and conducting an elephant presence-absence history record for each grid, using 1 for presence and 0 for absence (Royle and Nichols 2003; Tropical Ecology Assessment and Monitoring Network, 2008). Calculate the occupancy ( $\psi)$, probability of classification $(r)$, the abundance of animals from camera traps within each grid $(\lambda)$ for each location with $95 \%$ confidence interval, as well as the Akaike's Information Criterion (AIC) and calculate the abundance of the species of interest using the Presence 12.0 program (MacKenzie et al. 2006).

7. Analyze the population structure of the wild Asian elephants from the camera traps, the reproductive rate, and the recruitment rate (Dhungel 1985; Bhumpakphan 2006).
7.1. Reproductive rate was calculated by multiplying the number of elephant calves by 100 and dividing by the number of adult female elephants (Bhumpakphan 2006).

$$
\text { Reproduction rate }=\frac{\text { Number of elephant calves }}{\text { Number of adult female elephants }} \times 100 \%
$$

7.2. Recruitment rate was calculated by adding the number of juvenile elephants and calves, and dividing by the number of adult male and adult female elephants' times 100 (Bhumpakphan 2006).

Recruitment rate $=\frac{\text { Number of juvenile elephants+Number of calves }}{\text { Number of adult males +number of adult females }} \times 100 \%$

8. The habitat use was analyzed using MaxEnt to find a suitable habitat from the data obtained from camera traps in relation to the environmental factors that affect habitat selection.

8.1. GPS locations of the camera trap that recorded elephant presence and the 5 large even-toed ungulate species were imported and used to find the relation with other environmental factors.

8.2. The environmental factors were divided into 2 groups including biological environmental factors, which are the plant society types, and 10 physical environmental factors including elevation, slope, and distance from artificial water sources, natural water sources, saltlicks, agricultural land, transportation routes, ranger stations, community area, and elephant-proof moats.

8.3. The data from 8.1 and 8.2 were then converted into raster data for analysis. The two types of data include (1) continuous data which consists of elevation, slope, distance from artificial water sources, natural water sources, saltlicks, agriculture land, transportation routes, ranger stations, community area and elephant-proof moats, and (2) category data including plant society.

8.4. A model of the distribution and probability of occurrence in the habitat relating to the environmental factors of wild elephants was then produced by dividing the data set into 2 sets with a 75: 25 ratios, $75 \%$ was the data tested with the MaxEnt program and 25\% was for data verification.

8.5. The equal training sensitivity and specificity used the logistic threshold criteria to divide the data into presence and absence, and the percentage contribution of each environmental factor from testing the model, which shows the evaluation of the relationship between the animal presence locations and the main environmental factors (Phillips and Dudik 2008).

9. The diel activity pattern of the wild Asian elephants and the 5 species of large even-toed ungulates including the gaur, banteng, sambar deer, red muntjac and wild boar was analyzed by summarizing the information on the foraging time that was obtained from the camera traps, and dividing the time period into 24 hours

9.1 Use the data to plot an activity graph to calculate the relation of diel activity pattern between the elephants and the 5 species of large even-toed ungulates.

9.2 Consider each species' activity using camera trap photographs recorded each hour. All images must be 
independent from each other within the day. The method for analyzing the probability of the overlapping diel activity patterns of each species was applied from Ridout and Linkie (2009). The evaluation of the diel activity pattern of each species was performed by the $\mathrm{R}$ program using the Kernel density equation or adding trigonometric distributions (Fernandez-Duran 2004). The temporal overlap analyses were performed in the $\mathrm{R}$ program $(\mathrm{R}$ Development Core Team 2016) using the "overlap" package (Meredith and Ridout 2014)

9.3 The overlap of the diel activity patterns of two animal species of interest were calculated using the overlap coefficient or $\Delta$, which means the area under the curved line which occurs from 2 points of the lowest density in each period. The overlap coefficient will be equal to 1 when the density of the activity is the same, and will be equal to 0 when no activities overlap (Ridout and Linkie 2009). The confidence interval is the percentage of the time period obtained by repeated sampling, or bootstrap, 10,000 times at $95 \%$ confidence intervals and using the overlap coefficient $\Delta$ following Ridout and Linkie (2009), because of the large sample size using the $\mathrm{R}$ program ( $\mathrm{R}$ Development Core Team 2016).

\section{RESULTS AND DISCUSSION}

The 58 camera traps deployed, equal to 4,463 trap nights, recorded a total of 3,745 photographs of wild animals. Dividing the photographs into elephants and 5 species of even-toed ungulates resulted in 1,706 photographs, including 469 individual photographs of wild elephants, 583 photographs of wild boar, 274 photographs of sambar deer, 155 photographs of gaur, 117 photographs of banteng and 108 photographs of red muntjacs. The total trap nights for each species are shown in Table 1. The relative abundance index (RAI) of the wild Asian elephant was $10.74 \%$. The RAI for the wild boar was $14.84 \%$, followed by Sambar deer $(10.92 \%)$, banteng $(6.42 \%)$, gaur $(5.97 \%)$, and red muntjac (3.38\%).

\section{Patch occupancy}

In this study, 469 photographs of wild elephants were obtained from 53 camera trap locations, which equals $91 \%$ of the total camera trap locations. The all year patch occupancy from March 2017 to March 2018, from the 53 camera trap locations, was $91 \% \quad(\mathrm{SE}=0.55)$, with the abundance of 1.14 animals $/ \mathrm{km}^{2}(\mathrm{SE}=0.25)$. The number of elephants all year round in the $88.12 \mathrm{~km}^{2}$ study area, when extending the area with a radius of $1 \mathrm{~km}$ from the camera trap location, was 174.43 elephants (Table 2). In the dry season from March 2017 to April 2017 and December 2017 to March 2018, from 21 camera trap locations, the patch occupancy was $95 \%(\mathrm{SE}=0.83)$ with an abundance of 2.04 animals $/ \mathrm{km}^{2}(\mathrm{SE}=0.70)$ and a total of 161.72 elephants. In the wet season, from 44 camera trap locations, the patch occupancy value was $97 \%(\mathrm{SE}=0.04)$, with an abundance of 3.78 animals $/ \mathrm{km}^{2}(\mathrm{SE}=1.79)$ and a total of 166.32 elephants (Table 2). For the other species in the area, the wild boar had a patch occupancy of $0.72(\mathrm{SE}=0.06)$ and an abundance of 1.27 animals $/ \mathrm{km}^{2}(\mathrm{SE}=0.20)$. The red muntjac had a patch occupancy of $0.70(\mathrm{SE}=0.08)$ and an abundance of 1.22 animals $/ \mathrm{km}^{2}(\mathrm{SE}=0.29)$. The gaur had a patch occupancy of $0.54(\mathrm{SE}=0.07)$ and an abundance of 0.79 animals $/ \mathrm{km}^{2}(\mathrm{SE}=0.15)$ the banteng had a patch occupancy of $0.43(\mathrm{SE}=0.07)$ and an abundance of 0.56 animals $/ \mathrm{km}^{2}$ $(\mathrm{SE}=0.12)$. The sambar deer had a patch occupancy of 0.46 $(\mathrm{SE}=0.06)$ and an abundance of 0.62 animals $/ \mathrm{km}^{2}$ $(\mathrm{SE}=0.12)$. Another ungulate species found was the mouse deer, which had a patch occupancy of $0.23(\mathrm{SE}=0.06)$ and an abundance of 0.26 animals $/ \mathrm{km}^{2}(\mathrm{SE}=0.08)$ (Table 3$)$.

Table 1 Number of photographs and trap nights of wild elephants and 5 large even-toed ungulate species in Khao Ang Rue Nai Wildlife Sanctuary, Chachoengsao Province, Thailand

\begin{tabular}{llccc}
\hline $\begin{array}{l}\text { Common } \\
\text { name }\end{array}$ & Scientific name & $\begin{array}{c}\text { Number of } \\
\text { photos }\end{array}$ & $\begin{array}{c}\text { trap } \\
\text { nights }\end{array}$ & \% RAI \\
\hline Asian elephant & Elephas maximus & 469 & 4.364 & 10.74 \\
Gaur & Bos gaurus & 155 & 2.594 & 5.97 \\
Banteng & Bos javanicus & 117 & 1.823 & 6.42 \\
Sambar deer & Rusa unicolor & 274 & 2.509 & 10.92 \\
Wild boar & Sus scrofa & 583 & 3.929 & 14.83 \\
Muntjac & Muntiacus muntjak & 108 & 3.191 & 3.38 \\
Total & & 1.706 & 18.410 & 52.26 \\
\hline
\end{tabular}

Table 2. The abundance of elephants in Khao Ang Rue Nai Wildlife Sanctuary, Chachoengsao Province from the Probability Occupancy study

\begin{tabular}{lcccc}
\hline & $\begin{array}{c}\text { Naïve } \\
\text { occupancy }\end{array}$ & $\boldsymbol{\psi} \pm \mathbf{S E}^{\mathbf{2}}$ & $\boldsymbol{\lambda} \pm \mathbf{S E}^{\mathbf{3}}$ & $\mathbf{N}^{4}$ \\
\hline All year & 0.51 & $0.91 \pm 0.55$ & $1.14 \pm 0.25$ & 174.43 \\
The dry season & 0.57 & $0.95 \pm 0.83$ & $2.04 \pm 0.70$ & 161.72 \\
The wet season & 0.95 & $0.97 \pm 0.04$ & $3.78 \pm 1.79$ & 166.32 \\
\hline
\end{tabular}

Note: 1. Number of sites in which a species was detected without cooperating detection probability. 2. Occupancy rate, or proportion of sites occupied. 3. The average cell-specific abundance. 4. Estimated abundance.

Table 3. Patch occupancy and abundance of other wildlife species

\begin{tabular}{lcccc}
\hline Common name & Naïve occupancy $^{1}$ & $\boldsymbol{\psi} \pm \mathbf{S E}^{2}$ & $\boldsymbol{\lambda} \pm \mathbf{S E}^{3}$ & $\mathbf{N}^{4}$ \\
\hline Asian elephant & 0.68 & $0.72 \pm 0.06$ & $1.27 \pm 0.20$ & $73.71 \pm 11.46$ \\
Gaur & 0.63 & $0.70 \pm 0.08$ & $1.22 \pm 0.29$ & $70.48 \pm 16.54$ \\
Banteng & 0.46 & $0.54 \pm 0.07$ & $0.79 \pm 0.15$ & $45.60 \pm 8.59$ \\
Sambar deer & 0.38 & $0.46 \pm 0.06$ & $0.62 \pm 0.12$ & $35.97 \pm 6.75$ \\
Wild boar & 0.38 & $0.43 \pm 0.07$ & $0.56 \pm 0.12$ & $32.25 \pm 7.09$ \\
Muntjac & 0.20 & $0.23 \pm 0.06$ & $0.26 \pm 0.08$ & $15.23 \pm 4.64$ \\
\hline
\end{tabular}

Note: 1. Number of sites in which a species was detected without cooperating detection probability. 2. Occupancy rate, or proportion of sites occupied. 3. The average cell-specific abundance. 4. Estimated abundance 
When compared with the results from Vinitpornsawan et al. (2015) the number of wild Asian elephants counted near water sources and saltlicks in Khao Ang Rue Nai Wildlife Sanctuary was 236 elephants, while the number counted outside the protected area was approximately 300 In particular, the Northern part in Chachoengsao and Prachinburi province had an estimated 100 elephants, in Rayong and Chonburi province there were approximately 50 elephants and in Chanthaburi province, especially in Kaeng Hang Maew district, there were approximately 100 elephants. The total number of wild Asian elephants counted was 364 elephants approximately that based on direct counting.

\section{Population structure}

Results obtained from 140 camera trap photographs showed the elephant population structure of adult, subadult, juvenile, and calf to be $77.85 \%, 5.71 \%, 9.28 \%$, and $7.14 \%$, respectively (Table 4 ). The ratio between calf, juvenile, sub-adult, and adult was 1: 1.3: 0.8: 11.3 (Table 4). Comparing to the results from the camera trap photographs in 2010, studied by Department of Forest Biology (unpublished data) with a total of 7,560 trap nights covering an area of $813 \mathrm{~km}^{2}, 1,799$ photographs of elephants including 64 adults that the sex could not be determined, 914 adult females, 658 adult males, 50 subadults and 112 juveniles were recorded. The sex ratio between male and female was 1: 1.39, the ratio between female and calf was 1: 0.12 and the ratio between calf and adult was $7.12 \%$. In this study, the ratio between the adult male and the adult female was 1: 0.48 . The reproductive rate or the ratio between adult and calf was 1: 0.3 as shown in Table 5. From Table 4, the proportion between adult and sub-adult in the population was $83.57 \%$, while between juvenile and calf in the population was $16.43 \%$, which can be calculated as a $19.66 \%$ population increase rate. The time from the mother elephant becoming pregnant until the calf weans are approximately 4-5 years (Sukmasuang 2009 ) or equal to $4.91-3.93 \%$ per year. The mortality of elephants has been reported occasionally both inside and around the protected area, especially when adult elephants leave the protected area (Wanghongsa et al. 2006; Faculty of Forestry 2013; Wattanaaungkool 2017).

Compared to the results from Vinitpornsawan et al. (2015) who studied elephant population by counting individuals directly within Khao Ang Rue Nai Wildlife Sanctuary, the ratio between adult male and female elephants was 1: 1.7 and the reproduction rate or the ratio between adult females and calves was 1: 0.3. Furthermore, Chaiyarat et al. (2015) conducted a study by camera trapping and found that the ratio between adult males and females was 1: 1.1 and the reproduction rate or the ratio between adult females and calves was 1: 0.3 , which is similar to the results of this study, meaning than if there are 10 adult female elephants then there will be 3 calves.

\section{Elephant habitat selection and use}

Habitat selection was analyzed using data obtained from camera trap photographs within Khao Ang Rue Nai
Wildlife Sanctuary, together with data of the biological environmental factors, which are plant society types and 10 physical environmental factors including (1) slope, (2) elevation, (3) distance from artificial water sources, (4) agricultural land, (5) transportation routes, (6) natural water sources, (7) ranger stations, (8) elephant-proof moats (9) community area and (10) saltlicks, using Maximum Entropy in the MaxEnt program. We found that the probability of occurrence of elephants over the whole year, during the dry season and the wet season relates to different environmental factors as follows.

When considering the annual data from 53 camera locations, the analysis showed that the AUC indicates an accuracy of 0.92 , meaning that the model was highly reliable with 92\% accuracy (Fawcett 2006). When considering the environmental factors that relate to the occurrence of the elephants from the percentage contribution over the year from March 2017 to March 2018, we found that the distance from the saltlicks was the environmental factor that had the most influence on the elephants $(42.4 \%)$, followed by the area slope (14.8\%) and the distance from artificial water sources (12.9\%) (Table 6). Other environmental factors had less relation to the presence of elephants over the year. Analyzing results of the distribution of the probability of occurrence of wild elephant over the year from the data obtained from camera traps placed in Khao Ang Rue Nai Wildlife Sanctuary, which covered an area of $1,064.44 \mathrm{~km}^{2}$. We could divide the area into areas with high probability of elephant presence, at approximately $94.51 \mathrm{~km}^{2}$, especially near the 3,259 road that cuts through the study area and the area around Khao Ang Rue Nai Wildlife Sanctuary headquarters. The area with a moderate probability of elephant presence was approximately $247.70 \mathrm{~km}^{2}$ and the area with a low probability of elephant presence was approximately $722.23 \mathrm{~km}^{2}$. However, we also found an area of approximately $6.23 \mathrm{~km}^{2}$ outside Khao Ang Rue Nai Wildlife Sanctuary with a probability of elephant presence.

Table 4 The population structure of elephants in Khao Ang Rue Nai Wildlife Sanctuary within the study period between March 2017 and March 2018.

\begin{tabular}{lcccc}
\hline Age class & Adult & Subadult & Juvenile & Calf \\
\hline $\begin{array}{l}\text { Number } \\
\text { of photos }\end{array}$ & $\mathbf{1 0 9}$ & $\mathbf{8}$ & $\mathbf{1 3}$ & $\mathbf{1 0}$ \\
\hline Ratio & 1 & 1.3 & 0.8 & 11.3 \\
Percentage & 77.85 & 5.71 & 9.28 & 7.14 \\
\hline
\end{tabular}

Table 5. Proportion between adult male and female, reproductive rate of adult female, adult per calf ratio and the recruitment rate of the elephants which could be classified using camera traps

\begin{tabular}{lcccc}
\hline \multirow{2}{*}{ Age class } & \multicolumn{2}{c}{$\begin{array}{c}\text { Adult male: Adult } \\
\text { female ratio }\end{array}$} & \multicolumn{2}{c}{$\begin{array}{c}\text { Adult female: } \\
\text { calf ratio }\end{array}$} \\
\cline { 2 - 5 } & AM & AF & AF & CL \\
\hline Number of photos & 62 & 30 & 30 & 10 \\
Ratio & 1 & 0.48 & 1 & 0.3 \\
\hline
\end{tabular}

Note: AM: Adult male; AF: Adult female; CL: Calf 
Table 6. Percentage contribution of the environmental factors on elephant presence over the year shows the elephant presence was influenced by environmental factors.

\begin{tabular}{lccc}
\hline \multirow{2}{*}{ Environmental factors } & \multicolumn{3}{c}{ Percentage contribution } \\
\cline { 2 - 4 } & Total & $\begin{array}{c}\text { Dry } \\
\text { season }\end{array}$ & $\begin{array}{c}\text { Wet } \\
\text { season }\end{array}$ \\
\hline Distant from salt lick & 42.4 & 43.5 & 37.0 \\
Distant from artificial water sources & 12.6 & 11.2 & 20.0 \\
Slope & 14.8 & 11.4 & 18.0 \\
Distance from agriculture land & 2.7 & 3.1 & 9.8 \\
Distance from transportation routes & 7.0 & 6.5 & 6.5 \\
Distance from natural water sources & 0.7 & 0.8 & 0.8 \\
Distance from ranger station & 0.3 & 0.4 & 0.3 \\
Distance from elephant moat & 10.9 & 13.0 & 9.8 \\
Elevation & 7.7 & 8.7 & 5.8 \\
Distance from community area & 0.2 & 0.6 & 0.3 \\
Evergreen forest within the wildlife & 0.5 & 0.7 & 0.6 \\
sanctuary & & & \\
Total & 100.00 & 100.00 & 100.00 \\
\hline
\end{tabular}

The dry season in this study was from March to April 2017, and from December 2017 to March 2018. Model analysis from the 21 camera trap locations found that the AUC was very near 1 (0.959), which indicates that this model describes the reliability of the elephant habitat use model to be $95.9 \%$ (Fawcett 2006). When considering the environmental factors that are related to the probability of presence of the wild elephants from the percentage contribution in the dry season, it was found that the distance from artificial water sources was the factor most related to the presence of wild elephants $(41.9 \%)$, followed by the distance from saltlicks $(25 \%)$ and the slope $(7.5 \%)$. The other environmental factors were less related to elephant presence in the year. The distribution of the wild elephant probability of presence in the dry season, obtained from camera traps placed within the $1,064.44 \mathrm{~km}^{2}$ of Khao Ang Rue Nai Wildlife Sanctuary, showed the area could be divided into areas that have a high possibility of elephant presence at approximately $51.15 \mathrm{~km}^{2}$, an area with moderate possibility at approximately $165.51 \mathrm{~km}^{2}$, and areas with low possibility at approximately $847.77 \mathrm{~km}^{2}$. However, it was also found the there was an area of 6.77 $\mathrm{km}^{2}$ outside Khao Ang Rue Nai Wildlife Sanctuary that had a possibility of wild elephant presence in the dry season.

For the rainy season, between May 2017 and November 2017, data were obtained from 44 camera trap locations. The model analysis showed the AUC value was very close to $1(0.927)$ which indicates that this model describes the reliability of the elephant habitat use model to be $92.7 \%$ (Fawcett 2006). When considering the environmental factors that are related to the probability of presence of the wild elephants from the percentage contribution, it was found that the distance from artificial water sources was the factor most related to the presence of wild elephant (38.8\%), followed by the distance from saltlicks $(22.9 \%)$ and the distance from agriculture land $(13.8 \%)$. The other environmental factors were less related to elephant presence in the year. From the distribution of wild elephant probability of presence from the camera traps placed within an area of $348.44 \mathrm{~km}^{2}$, the area could be divided into areas that have a high possibility of elephant presence at approximately $94.92 \mathrm{~km}^{2}$, and the area with moderate possibility at approximately $253.52 \mathrm{~km}^{2}$. However, it was also found that there was an area of $0.03 \mathrm{~km}^{2}$ outside of Khao Ang Rue Nai Wildlife Sanctuary that had a possibility of wild elephant presence.

The results of wild elephant habitat use in Khao Ang Rue Nai Wildlife Sanctuary, Chachoengsao Province all year round, in the dry season and in the wet season show that the distance from saltlicks and the distance from artificial water sources gave the highest probability of wild elephant occurrence, which was consistent with the study by Chaiyarat et al. (2015), who studied wild elephant habitat use in Salakpra Wildlife Sanctuary, Kanchanaburi Province between May 2010 and March 2011. The analysis of the RAI of wild elephants from photographs showed that artificial water sources had the highest RAI followed by saltlicks.

\section{Activity cycle}

The highest activity of wild elephants was seen during the night between 18: 00 and 05: 59, which was shown in 398 photographs or $85 \%$ of the 469 photographs recorded (Table 7). This shows that they have strong nocturnal activities similar to gaurs, bantengs, and sambar deer, while wild boars and muntjacs have mostly diurnal activity. The highest activity was between 18: 00 and 22: 00, which is in accordance with the study by Vinitpornsawan et al. (2015) who found that elephants in the Eastern forest complex have foraging activities from dusk to before dawn, with the highest activities during 17: 30 to 22: 00. Furthermore, it is also consistent with the studies from Pla-ard (2017), who reported the presence of elephants in Khao Yai National Park to be highest during 16: 00 to 20: 00 and Baskaran et al. (2010) who found that the foraging time of elephants was in the mornings from 06: 00 to 09: 00 and in the evenings from 15: 00 to 17: 00 . When assessing the relation of the diel activity patterns between wild elephants and each large even-toed ungulate species using the kernel density equation and the overlap coefficient $(\Delta)$, it shows that gaurs had the most overlapping diel activity cycles with the wild elephants, equal to a positive significant overlap value of 0.87 or $87 \%(r=0.87, P<0.05)$. Banteng had a significant overlap value of 0.70 or $70 \%(r=0.70, P$ $<0.05)$. Sambar deer had a non-significant overlap value of 0.66 or $66 \%(\mathrm{r}=0.62, P>0.05)$. Red muntjac had a negative overlapping diel activity cycle equal to a significant value of 0.55 or $55 \%(\mathrm{r}=-0.55, P<0.05)$ and the wild boar had a negative significant value of 0.74 or $74 \%$ ( $\mathrm{r}=-0.74, P<0.05$ ) (Table 8 ). The diel activity patterns and the overlap between wild elephants and the 5 species of large even-toed ungulates were also shown in Figure 2. The results of the diel activity cycle of wild Asian elephants during 2017 to 2018, which was during the problematic period of elephants leaving the protected area, revealed that the highest activity of the elephants was from 18: 00-24: 00, which was consistent with Thomas and Phan (2011) who reported that wild elephants' activities were cathemeral. 
Table 7. Activity cycle of wild elephants and 5 large even-toed ungulate species in Khao Ang Rue Nai Wildlife Sanctuary.

\begin{tabular}{lcccccc}
\hline Common name & $\begin{array}{c}\text { Number of } \\
\text { photos taken } \\
\text { during day time }\end{array}$ & $\begin{array}{c}\text { \% of photos } \\
\text { present during } \\
\text { day time }\end{array}$ & $\begin{array}{c}\text { Number of photos } \\
\text { taken during night } \\
\text { time }\end{array}$ & $\begin{array}{c}\text { \% of photos } \\
\text { present during } \\
\text { night time }\end{array}$ & $\begin{array}{c}\text { Number of } \\
\text { photos in } \\
\text { total }\end{array}$ & $\begin{array}{c}\text { Note1 } \\
\text { Elephant }\end{array}$ \\
Gaur & 23 & 15 & 398 & 85 & 469 & $\mathrm{Sn}$ \\
Banteng & 18 & 15 & 132 & 85 & 155 & $\mathrm{Sn}$ \\
Sambar deer & 40 & 15 & 99 & 85 & 117 & $\mathrm{Sn}$ \\
Red muntjac & 73 & 15 & 234 & 85 & 274 & $\mathrm{Sn}$ \\
Wild boar & 440 & 75 & 143 & 32 & 108 & $\mathrm{Md}$ \\
\hline
\end{tabular}

Note: $\mathrm{Sn}=$ Strongly nocturnal. Md = Mostly diurnal

Table 8. Spearman Rank correlation of daily activity patterns and overlap between wild elephants and the 5 species of large even-toed ungulates (at 0.05 significance level).

\begin{tabular}{lcccccc}
\hline & Elephant & Gaur & Banteng & Sambar deer & Red muntjac & Wild boar \\
\hline Elephant & 1 & - & - & - & - & - \\
Gaur & $0.87^{*}$ & 1 & - & - & - & - \\
Banteng & $0.70^{*}$ & $0.69^{*}$ & 1 & - & - & - \\
Sambar deer & $0.62^{*}$ & $0.62^{*}$ & $0.60^{*}$ & 1 & - & - \\
Red muntjac & $-0.55^{*}$ & -0.29 & -0.35 & -0.25 & $-0.65^{*}$ & 1 \\
Wild boar & $-0.74^{*}$ & $-0.60^{*}$ & $-0.65^{*}$ & & & 1 \\
\hline
\end{tabular}

Note: * Significance was determined at $\mathrm{P}<0.05$

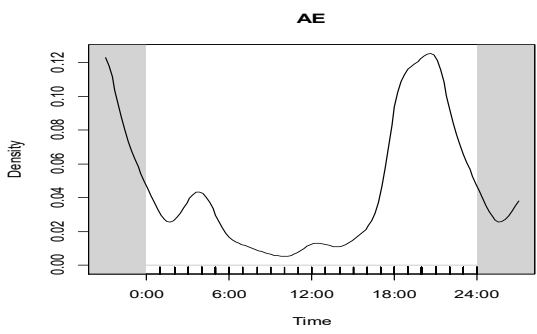

$\mathbf{A}$

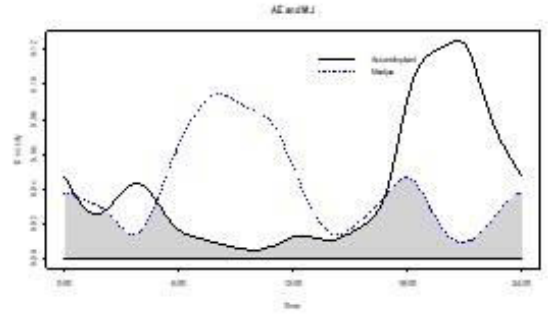

$\mathbf{E}$

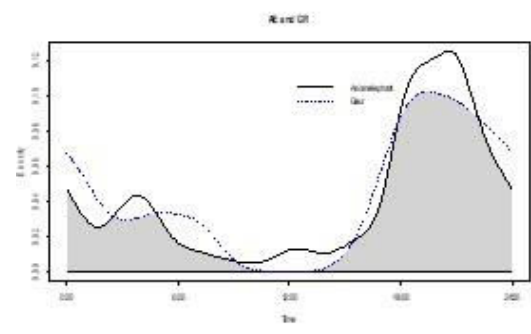

B

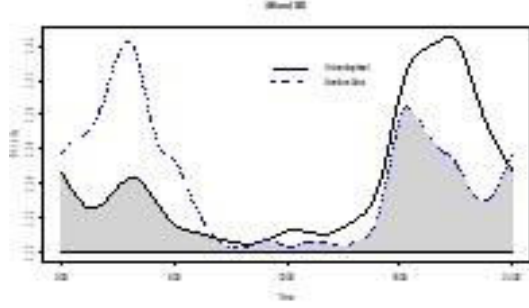

$\mathbf{F}$

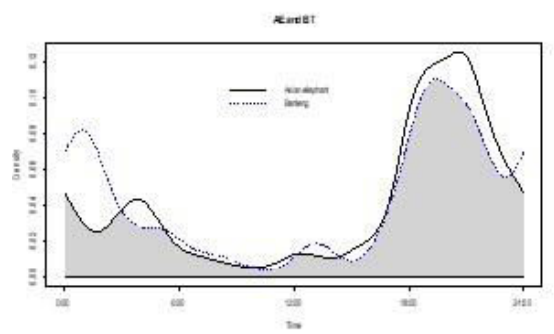

C

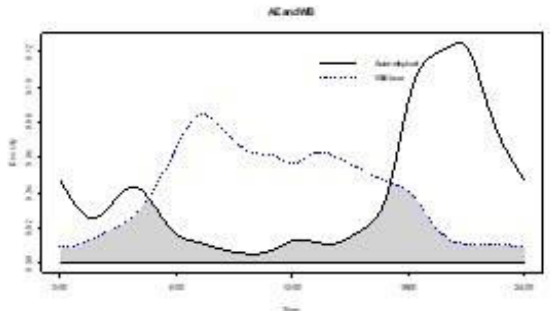

G

Figure 2. The diel activity patterns and the overlap between wild elephants and the 5 species of large even-toed ungulates. The solid line shows the kernel-density of wild elephants, and the dashed lines show the kernel-density of the other species. A. Diel activity cycle of wild elephants, B. Elephant and gaur, C. Elephant and banteng, D. Elephant and red muntjac, E. Elephant and sambar deer, F. Elephant and wild boar

\section{Conclusion and recommendation}

The annual occupancy of the wild Asian elephant population was $0.92 \quad(\mathrm{SE}=0.04)$, while it was 0.97 $(\mathrm{SE}=0.04)$ in the dry season and was $0.90(\mathrm{SE}=0.83)$ in the wet season. The number of elephants in the study area $\left(87.95 \mathrm{~km}^{2}\right)$ ranked between 79.51 and 334.15 . The proportion of the adult elephants, sub-adults, juvenile and calves were $77.85,5.71,9.28$ and $7.14 \%$, respectively. The ratio between male and female was 1: 0.48 , while the ratio between females and calves was 1: 0.3 indicating the increasing tren of elephant population at Khao Ang Rue Nai Wildlife Sanctuary. 
Distance to artificial (man-made) water sources and distance to saltlicks were important factors for habitat use of elephant. These two factors contributed to $65.0 \%$ of the total habitat factors. In addition, distance to artificial water source remained the highest contributor followed by distance to salt licks both in the dry and the wet seasons but the percentages of contribution slightly decreased in the wet season. In addition, distance to agricultural area was a considerable factor. These results imply that the existing development and improvement of water sources and artificial salt licks by various agencies along the sanctuary boundaries could stimulate the elephant to go outside the sanctuary and create more conflicts with local people. These practices should be conducted inside the sanctuary.

In addition, agriculture crops (e.g., pipe apple, sugar cane) should be grown at least $1 \mathrm{~km}$ from the border of the protected area to reduce the encouragement for elephants to leave the parks. Forest plantation or agroforestry is recommended.

The study also shows that Khao Ang Rue Nai Wildlife Sanctuary still has a high number of large herbivores, especially gaur, banteng, sambar deer, muntjac, and wild boar and they have usual activity and live within the protected area rather than outside. This indicates the potential of the area to be a suitable habitat for large wildlife species and elephants. Therefore, increase in management measures both in area management for elephants to come back inside and to continue to publicize the relevant actions, especially the management of agricultural plants around the protected area, the use of highways that pass through the wildlife sanctuary and reaching an understanding with villagers on the management of the area.

\section{ACKNOWLEDGEMENTS}

This study was funded by the National Research Council of Thailand (NRCT). The grant was under the activities promoting and supporting research plan, for the potential development of new graduate researchers, NRCT as the fiscal year of 2018. We would like to thank the head of the Forest Biology Department and the dean of the Faculty of Forestry who supported this study. We also would like to thank the head of Chachoengsao Wildlife Research Station, the head of Khao Ang Rue Nai Wildlife Sanctuary and the head of Forest Preservation Protection Base (Khao Ka) for the accommodation and support staff to help with the operation.

\section{REFERENCES}

Arivazhagan C, Sukumar R 2008. Constructing age structure of Asian elephant populations: a comparison of two field methods of age estimation. Gajah 29: 11-16.

Azlan MJ, Sharma DSK. 2006. The diversity and activity patterns of wild felids in a secondary forest in Peninsular Malaysia. Oryx 40: 36-41.

Barnes JI. 1996. Changes in the economic use value of elephant in Botswana: the effect of international trade prohibition. Ecol Economics 18 (3): 215-230.
Baskaran N, Balasubramanian M, Swaminathan S, Desai AA. 2010. Feeding ecology of the Asian elephant Elephas maximus Linnaeus in the Nilgiri Biosphere Reserve, Southern India. J Bombay Nat Hist Soc 107 (1): 3-13

Bhumpakphan N. 2006. Wildlife Ecology. Department of Forest Biology, Faculty of Forestry, Kasetsart University. Bangkok. (in Thai).

Chaiyarat R, Youngpoy N, Prempree P. 2015. Wild Asian elephant Elephas maximus population in Salakpra Wildlife Sanctuary, Thailand. Endang Species Res 29: 95-102.

Department of Forest Biology. 2019. Camera trap raw data at Khao Ang Rue Nai Wildlife Sanctuary. Faculty of Forestry, Kasetsart University, Bangkok.

Department of Land Development. 2016. Land use map of Khao Ang Rue Nai Wildlife Sanctuary. Ministry of Agriculture and Cooperatives. Bangkok.

Durant SM. 1998. Competition refuges and coexistence: an example from Serengeti carnivores. J Anim Ecol 67: 370-386.

Dhungel, S. 1985. Ecology of the Hog Deer in Royal Chitwan National Park. [Ph.D. Dissertation]. Montana University.

Faculty of Forestry. 2013. Elephant Conservation and Management Plan. Faculty of Forestry, Kasetsart University. Bangkok. (in Thai).

FAO. 2009. Human-wildlife conflict in Africa conflict in Africa Causes, consequences Causes, consequences and management strategies and management strategies. Available source: http: //www.fao.org/3/i1048e/i1048e00.pdf. [May 2019].

Fawcett T. 2006. An introduction to ROC analysis. Pattern Recognit Lett 27: 861-874.

Fernandez-Duran JJ. 2004. Circular distributions based on nonnegative trigonometric sums. Biometrics 60: 499-503.

Hedges S, Fisher K, Rose R. 2008. Range-wide mapping workshop for Asian elephants (Elephas maximus), Cambodia. A report to the U.S. Fish \& Wildlife Service on Assistance Award No: 98210-6-G232. Phnom Penh.

MacKenzie, D.I., J.D. Nichols, J.A. Royle, K.H. Pollock, L.L. Bailey, and J.E. Hines. 2006. Occupancy Estimation and Modeling: Inferring Patterns and Dynamics of Species Occurrence. Academic Press, Burlington, Massachusetts.

Madhusudan MD. 2003. Living amidst large wildlife: livestock and crop depredation by large mammals in the interior villages of Bhadra Tiger Reserve, South India. Environ Manag 31 (4): 466-475.

Meredith M, Ridout MS. 2014. Overlap: estimates of coefficients of overlapping for animal activity patterns. $\mathrm{R}$ package version 0.2. 22014.

O' Brien TG, Kinnaird MF, Wibisono HT. 2003. Crouching tigers, hidden prey: Sumatran tiger and prey populations in a tropical forest landscape. Anim Conserv 6: 131-139.

Kawanishi K, Sahak AM, Sunquist M. 1999. Preliminary analysis on abundance of large mammals at Sungai Relau, Taman Negara. J Wildl Parks (Malaysia) 17: 62-82.

Phillips SJ, Dudík M. 2008. Modeling of species distributions with MaxEnt: New extensions and a comprehensive evaluation. Ecography 31: 161-175.

Pla-ard M. 2017. Population and Habitat Use of Wild Elephant in Khao Yai National Park. [M.E. Thesis]. Kasetsart University.

R Development Core Team. 2016. R: A Language and Environment for Statistical Computing. R Foundation for Statistical Computing, Vienna.

Ridout MS, Linkie M. 2009. Estimating overlap of daily activity patterns from camera trap data. J Agric Biol Environ Stat 14: 322-327.

Rovero, F. and A.R. Marshall. 2009. Camera trapping photographic rate as an index of density in forest ungulates. J Appl Ecol 46: 1011-1017.

Royle JA, Nichols JD. 2003. Estimating abundance from repeated presence-absence data or Point counts. Ecology 84: 777-790.

Rowcliffe, J. M., and C. Carbone. 2008. Surveys using camera traps: Are we looking to a brighter future? Anim Conserv 11: 185-186.

Seoraj-Pillai N, Pillay N. 2017. A meta-analysis of human-wildlife conflict: South African and global perspectives. Sustainability 9 (34): 1-21. DOI: $10.3390 / \mathrm{su} 9010034$

Sukmasuang R. 2009. Population density of Asian elephants in Huai Kha Khaeng Wildlife Sanctuary. Thai J Forest 28 (1): 40-50.

Thai Meteorological Department. 2015. The Climate of Thailand (based on 1951-2015). Available source: https: //www.tmd.go.th/en/archive/thailand_climate.pdf. Download on $10^{\text {th }}$ June 2019. 
Thomas NEG, Phan C. 2011. Habitat preferences and activity patterns of the larger mammal community in Phnom Prich Wildlife Sanctuary, Cambodia. Raffles BullZool. 59 (2): 311-318.

Treves A, Naughton-Treves L. 1999. Risk and opportunity for humans coexisting with large carnivores. J Hum Evol 36: 275-282.

Tropical Ecology Assessment and Monitoring Network. 2008.Terrestria Vertebrate (Camera Trap) Monitoring Protocol Implementation Manual. Tropical Ecology, Assessment and Monitoring Network, Center for Applied Biodiversity Science, Conservation International, Arlington, VA, USA.

Varma S, Baskaran N, Sukumar R. 2012. Field Key for Elephant Population Estimation and Age and Sex Classification. Asian Nature Conservation Foundation, Innovation Centre, Indian Institute of Science, Bangalore.

Varma S, Pittet A, Jamadagni HS. 2006. Experimenting usage of cameratraps for population dynamics study of the Asian elephant Elephas maximus in southern India. Curr Sci 91: 324-331.
Wanghongsa S. 2004. Elephant Population Survey Manual. Faktong Graphics \& Screen, Prachinburi Thailand.

Wanghongsa S, Boonkird S, Boonkird K. 2008. Human-elephant conflicts in Khao Ang Rue Nai Wildlife Sanctuary. Wildl Yearbook 9: 17-32. [Thai].

Wanghongsa S, Senatham Y, Boonkird K, Saengsen D. 2006. Why do elephant bulls wander outside forest areas of Khao Ang Rue Nai Wildlife Sanctuary? Wildl Yearbook 7: 156-169. [in Thai]).

Vinitpornsawan S, Bunchornratana K, Pukhrua A, Panyawiwatanakul R. 2015. Population and age structure of wild Asian elephants in eastern forest complex. Wildl Yearbook 15: 89-111. [Thai].

Wattanaaungkool N. 2017. A Study of Conflict Management between Wild Elephants and Residents of Pha Wa Subdistrict, Kaeng Hang Maew District, Chanthaburi Province. Independent Study. M.P.A. (Local Government). Rambhai Barni Rajabhat University, Chanthaburi, Thailand 